\title{
ARTÍCULOS
}

\section{DOS DIRECCIONES DE UN MISMO CAMINO: EL HISPANOAMERICANISMO CULTURAL DE JOSÉ MARÍA CHACÓN Y CALVO.}

\author{
Ruxandra Guillama Camba \\ Universidad de Santiago de Compostela \\ ruguica@gmail.com
}

Resumen: Este trabajo tiene el propósito de contribuir a renovar el enfoque ofrecido hasta el momento sobre el hispanoamericanismo en José María Chacón y Calvo desde la perspectiva cultural. Chacón resulta esencial para comprender los vínculos que tuvieron lugar entre España y Cuba en la primera mitad del siglo XX por cuanto fue una figura clave en los contactos que se establecieron entre ambos lados del Atlántico. Su doble condición de investigador y diplomático le permitió acceder a la elite intelectual española convirtiéndose en un interlocutor de excelencia para el fomento de las relaciones culturales entre ambas naciones. Asimismo, trataremos de comprobar el grado de influencia que tuvo su experiencia española cuando se desempeñó como gestor cultural en la Secretaría de Educación cubana.

Palabras clave: José María Chacón y Calvo, redes culturales, diplomático, investigador, Instituto Hispano Cubano de Sevilla, secretaría cultural.

Tittle: TWO WAYS OF ONE SAME PATH: THE CULTURAL HISPANOAMERICANISM OF JOSÉ MARÍA CHACÓN Y CALVO.

Abstract: With the purpose of renewing the approach offered up to now on Hispanic Americanism in José María Chacón y Calvo, the issue will be addressed, with an emphasis on the cultural topic. His figure is essential to understand the links that took place between Spain and Cuba in the first half of the twentieth century. Chacón was key in the contact spaces that were established between both sides of the Atlantic. His double status as researcher and diplomat allowed him to access the Spanish intellectual elite and be an interlocutor of excellence with the aim of promoting cultural relations between both nations. We will check that his work in Cuba was influenced by his experience as a cultural agent in Spain.

Keywords: José María Chacón y Calvo, cultural networks, diplomat, researcher, Instituto Hispano Cubano de Sevilla, cultural secretariat.

\section{Introducción}

Afirmar en la actualidad que el cubano José María Chacón y Calvo (La Habana, 1892-1969) fue un hispanista es reiterar un hecho incuestionable. Partiendo de esa premisa, pretendemos plantear los elementos más significativos de su ideario y

Recibido: 03-08-2019

Aceptado: 11-09-2019

Cómo citar este artículo: GUILLAMA CAMBA, Ruxandra. Dos direcciones de un mismo camino: el hispanoamericanismo cultural de José María Chacón y Calvo. Naveg@mérica. Revista electrónica editada por la Asociación Española de Americanistas [en línea]. 2019, n. 23. Disponible en: $<$ http://revistas.um.es/navegamerica $>$. [Consulta: Fecha de consulta]. ISSN 1989-211X. 
cómo este influyó en su quehacer cultural. El hispanoameri-canismo es la esencia intelectual de Chacón. Sus intereses científicos, su obra y el modo en que desempeñó las diferentes funciones que ocupó a lo largo de su carrera, así lo demuestran. Es preciso añadir que en Chacón la esencia de la cubanidad fluía, sin complejos de ninguna índole, desde sus raíces españolas, en un panorama donde estos temas eran motivo de debate y reflexión. La búsqueda de la identidad nacional que se suscita en la recién constituida República en Cuba de inicios del siglo XX es asumida por el joven Chacón y Calvo desde una perspectiva de fusión entre la cultura española y cubana. La posibilidad de trasladarse a España le facilitó, bajo el "pretexto" de las labores diplomáticas, llevar a cabo una fructífera labor de investigación a lo largo de varios años. Esta experiencia no solo le permitió un conocimiento profundo de la realidad peninsular, sino también establecer vínculos con la intelectualidad de la época, hasta convertirse en una figura clave, de verdadero enlace, entre España y Cuba.

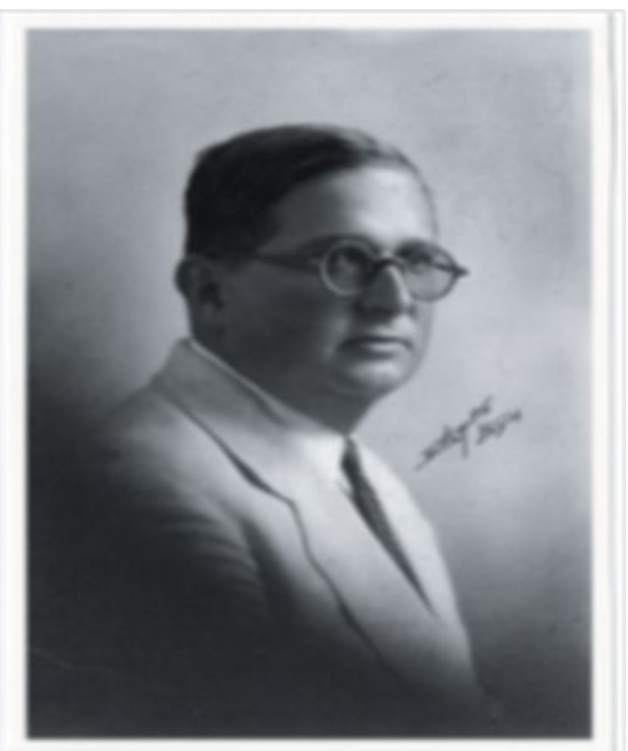

Fig. 1: José María Chacón y Calvo. Fuente: Archivo de la Universidad de Yale

En las próximas páginas, trataremos de interpretar el rol desempeñado por Chacón como diplomático, las redes culturales que estableció en su entorno, su papel como representante en Madrid de la Institución Hispano Cubana de Cultura de la Habana, sus vínculos con el Instituto Hispano Cubano de Sevilla y el proyecto cultural que materializó cuando desempeñó el cargo de director de la Secretaría de Educación cubana. De ahí que entre nuestros objetivos se encuentren no solo analizar la evolución del americanismo cultural de José María Chacón y Calvo, sino también establecer una renovada visión de las redes establecidas por el intelectual cubano. Para ello, resulta fundamental tomar en consideración las diferentes etapas de su carrera profesional que permiten visualizar los intereses en los que centró su labor y las multifacéticas aristas en que se desenvolvió. Se comprobará así que el eje común existente entre estos enfoques fue precisamente el hispanoamericanismo. 


\subsection{Estado de la Cuestión y Fuentes}

La aproximación historiográfica que se aborda a continuación se ha realizado desde una perspectiva cronológica, con el fin de apreciar el tratamiento efectuado por diferentes investigadores tanto a la figura como a la obra de Chacón a lo largo del tiempo. Así, por ejemplo, El trabajo de José Olivio Jiménez -Los cincuenta años de vida literaria de José María Chacón y Calvo'-, que supuso un temprano acercamiento a la figura del polígrafo cubano, tuvo como objetivo rendirle homenaje y reflejar algunos de los pasajes principales de su quehacer profesional. Este crítico literario señaló que, en lo que atañe a la obra de Chacón y Calvo, resulta frecuente que aparezca orientada hacia cuatro direcciones fundamentales: la crítica literaria, el ensayismo lírico, la investigación histórica y su infatigable labor como animador cultural ${ }^{2}$.

Como prueba fehaciente de una apuesta por el estudio del hispanoamericanismo en la figura que ocupa nuestro interés, cabe destacar el texto de la investigadora Zenaida Gutiérrez Vega titulado José María Chacón y Calvo. Hispanista Cubano ${ }^{3}$. Este libro supuso el punto de partida para otras publicaciones de la misma autora sobre Chacón ${ }^{4}$. A nuestro juicio, se trata de una obra detallada que, en el momento de su publicación, aportaba información inédita con la que ponía sobradamente de manifiesto el hispanoamericanismo chaconiano. No obstante, en ocasiones, pudiera parecer una historia de vida lineal de esas que nos acercan a un personaje impoluto, por otro lado comprensible por la cercanía de Gutiérrez Vega con Chacón y Calvo, o porque el texto, publicado en 1969, fue de las primeras creaciones de la autora. Gutiérrez Vega conoció el archivo personal de Chacón y, con su anuencia, llegó a convertirse en su biógrafa. Su copiosa y profunda obra permite, sin duda, afirmar que fue una auténtica experta en el tema. Entre los innumerables hitos acerca de Chacón relatados por esta autora se hace mención, por ejemplo, a sus antepasados que desde España arribaron a tierras cubanas en el siglo XVII, así como al título nobiliario del Condado de Casa Bayona que le fue otorgado a la familia. Sobre este asunto, hay que señalar que el padre de José María Chacón y Calvo nunca solicitó la restitución de dicho título, por tanto, para poder reactivarlo y mantener la tradición familiar, el polígrafo cubano inició los trámites pertinentes. Gutiérrez Vega ${ }^{5}$ señaló que "nuestro biografiado no pide la rehabilitación hasta el año 1950. Se lo impiden escrúpulos de sencillez y modestia"6. Sin embargo, hemos podido comprobar que en el periódico La Nación del 9 de octubre de 1918, fecha en la que José María Chacón estaba realizando funciones diplomáticas en España, ya se efectúa una alusión a su solicitud de rehabilitación del

\footnotetext{
1 JIMÉNEZ, José Olivio. Los cincuenta años de vida literaria de José María Chacón y Calvo. La Habana: Talleres del Archivo Nacional, 1964.

2 lbídem, p.6.

${ }^{3}$ GUTIERREZ VEGA, Zenaida. José María Chacón y Calvo. Hispanista Cubano. Madrid: Ediciones de Cultura Hispánica, Madrid, 1969.

${ }^{4}$ Además de la obra comentada se pueden mencionar de esta misma autora: Epistolario Adolfo Reyes- José María Chacón y Clavo (1976), Fernando Ortiz en sus cartas a José M. Chacón y Calvo (1982), Estudio Bibliográfico de José María Chacón y Calvo (1982), Corresponsales Españoles de José María Chacón y Calvo (1986).

${ }^{5}$ GUTIERREZ VEGA, Zenaida. José María Chacón y Calvo. Op. cit.

${ }^{6}$ GUTIERREZ VEGA, Zenaida. José María Chacón y Calvo. Op. cit., p. 22.
} 
título de Conde de Casa Bayona, por lo que no descartamos que hubiese empezado los trámites con antelación al momento que señala su biógrafa y que el proceso se dilatase en el tiempo debido a las gestiones burocráticas que conllevaba.

Durante su estancia en España a lo lardo de la década de los sesenta, Vega se adentró en la documentación que el intelectual cubano había dejado en su casa madrileña. Sobre los libros y escritos de Chacón que Gutiérrez Vega tuvo la ocasión de consultar nos parece oportuno comentar que se preservan actualmente en la Biblioteca Hispánica de la Agencia Española de Cooperación Internacional, considerado este uno los depósitos más importantes, junto con el Archivo del Instituto de Literatura y Lingüística de la Habana, donde se conserva información acerca del prominente cubano. No obstante, supimos por un artículo de la investigadora Carmen Ortiz ${ }^{7}$ que Zenaida Gutiérrez Vega llevó consigo una parte del archivo personal de Chacón y Calvo al abandonar España y dirigirse a Estados Unidos, también menciona que al fallecer esta le dejó dicha documentación a su colega cubano, Carlos Ripoll. A partir de estas pistas continuamos indagando al respecto, con el propósito de tener localizadas todas las fuentes primarias relacionadas con José María Chacón y Calvo. Fue así como supimos del deceso de Ripoll en el 2011, lo cual nos mantenía la incógnita acerca de dónde podían encontrarse los legajos que se sacaron de España. Otro elemento que corrobora que una parte del archivo personal de Chacón fue trasladado fuera de la península lo aporta el artículo de Diez Hoyo ${ }^{8}$. La autora al referenciar la colección de la mencionada Biblioteca Hispánica sobre Chacón y Calvo expresó que muchos de los documentos que Gutiérrez Vega menciona en su investigación, después de una exhaustiva búsqueda, se comprobó que no están entre los legajos que se atesoran en Madrid. Finalmente hemos constatado que la información que estuvo en posesión de Gutiérrez Vega se encuentra depositada en los archivos de la Universidad de Yale, en Estados Unidos. Queda así confirmado el destino, entre La Habana, Madrid y New Haven, de los documentos originales del polígrafo cubano.

Por su parte, la investigadora cubana, Malena Balboa, ha realizado varios estudios $^{9}$ que profundizan en la etapa en que Chacón ejerció como Director de Cultura en su país. Es necesario apuntar que el cubano se inició en dicha función cuando transcurría el mes de agosto de 1934 y que permaneció en su cargo durante siete meses, cuando cesaron sus funciones por decisión personal. En ese momento regresó a la península retomando su carrera diplomática lo que hizo coincidir su presencia con el inicio de la Guerra Civil Española. Después de abandonar España, porque su madre se puso enferma, retomó en febrero de 1937 sus funciones como Director de Cultura hasta diciembre de 1945. Una vez, acotada la trayectoria de la figura que nos ocupa, podemos agregar, que los trabajos de Balboa explican la

${ }_{7}$ ORTIZ, Carmen. Zenaida Gutiérrez -Vega hispanista Cubana. Revista de Indias. 2009, vol. LXIX, n. 247.

8 DíEZ HOLLO, María del Carmen. José María Chacón y Calvo en la Biblioteca Hispánica. Anuario Americanista Europeo. 2005, n. 3.

9 BALBOA PEREIRA P, Malena. Hacia una zona de convivencia de la cultura. José María Chacón y Calvo. Espacio Laical. 3/2011; BALBOA PEREIRA, Malena. Contra la indiferencia oficial. José María Chacón Calvo, director de cultura (1934-1945). La Habana: Editorial letras cubanas, 2013; BALBOA PEREIRA, Malena. José María Chacón y Calvo a la luz del pensamiento de Enrique José Varona. Cuadernos cubanos de Historia. Instituto de Historia de Cuba. 2015, vol. 22, n. 2. 
capacidad como gestor que desplegó Chacón y establecen los principales lineamientos culturales desarrollados por él en ese lapso de tiempo. Su visión se basa, entre otras fuentes, en la consulta del archivo del Instituto de Literatura y Lingüística de La Habana. Es preciso destacar que los artículos de Balboa se sustentan en una doble interpretación que abarca, tanto las prácticas como la obra escrita de Chacón, lo cual permite completar al unísono una perspectiva bastante completa acerca de la creatividad y el quehacer del polígrafo cubano durante ese período.

La institución en cuyas fuentes acerca de Chacón bosquejó M. Balboa, editó a comienzos del presente siglo El diario íntimo de la revolución española ${ }^{10}$ prologado precisamente por su directora, Nuria Gregori. Se ofrece ahí una mirada sobre la Guerra Civil Española desde las vivencias personales de Chacón y Calvo quien lo vivió en directo, como habíamos señalado. Este acontecimiento, de trascendental importancia en la historia del siglo XX, fue narrado a partir del quehacer diario del por entonces diplomático cubano y según, se avanza en las páginas del libro, se advierte de manera explícita la intención de Chacón de no inmiscuirse en temas políticos. Aun así, a Chacón y Calvo le preocupa -y se involucra- en la vorágine que supuso el contexto del conflicto español. En este sentido, cabe destacar que la obra Cuba y la guerra civil española. La voz de los intelectuales ${ }^{11}$, perteneciente a la colección "Hispanoamérica y la Guerra Civil española" recoge un fragmento de dicho diario como ejemplo de los incómodos momentos vividos por Chacón durante la contienda y su incansable labor por salvar vidas humanas.

Por su parte, en su artículo Breve recuento de la Revista Cubana ${ }^{12}$, el crítico literario Enrique Sainz realiza un análisis de la publicación fundada por Chacón y Calvo en el año 1935, en su primera etapa como Director de Cultura, antes de abandonar su cargo para regresar a España. Sainz consideró de vital importancia la edición de la revista como espacio de reflexión y creación en su época. También recalca que en dicho medio, en consonancia con las ideas de su fundador, se priorizó la tesis de neutralidad de la cultura lo cual no excluía la preocupación por la realidad nacional. Mientras se editó, la Revista Cubana (1935-1957), aportó diferentes contribuciones acerca de los valores artísticos, literarios e históricos del país, pero también resumió y validó los criterios de Chacón y Calvo como auténtico promotor de la publicación.

Recientemente, el trabajo titulado José María Chacón y Calvo o la cultura como diplomacia: Madrid, 1918-1936, firmado por Fernando Bruquetas de Castro ${ }^{13}$ presenta, tal y como reconoce el autor, una semblanza biográfica. En su aportación considera a Chacón y Calvo como el diplomático por antonomasia subrayando que,

\footnotetext{
10 GREGORI TORADA, Nuria. José María Chacón y Calvo. Diario íntimo de la Revolución Española. La Habana: Instituto de Literatura y Lingüística, 2006.

11 BINNS, Nial; CANO REYES, Jesús y CASADO FERNÁNDEZ, Ana. Cuba y la guerra civil española. La voz de los intelectuales. Madrid: Calambur, 2015.

12 SAINZ, Enrique. Breve recuento de la Revista Cubana. Revista Espacio Laical. 2018, año 14, n. 1.

${ }^{13}$ BRUQUETAS DE CASTRO, Fernando. José María Chacón y Calvo o la cultura como diplomacia: Madrid, 1918-1936. En: CAGIAO VILA, P. y ELÍAS CARO, Jorge Enrique (comps.). España como escenario. Política y acción cultural de diplomáticos (1880-1936). Santa Marta: Unimagdalena, 2018.
} 
a su juicio, la vocación central de su vida era la de historiador e investigador ${ }^{14}$. Pero, en nuestra opinión, la diplomacia no es la profesión o característica por la que se puede identificar a Chacón, aunque reconozcamos la oportunidad que representa para un representante del servicio exterior la posibilidad de intercambiar con colegas y personalidades del país en que se está acreditado. Como intentamos probar a lo largo de este trabajo, esa fue una tarea realizada con notable éxito por Chacón y Calvo. Es verdad que el cubano destacó fundamentalmente como investigador realidad que también menciona Bruquetas- pero fue precisamente su desempeño intelectual el que le facilitó el camino de la diplomacia. En otros aspectos relativos a su personalidad, Bruquetas de Castro alude al hecho de que Chacón y Calvo fue un hombre muy religioso y agrega que también, en cierta medida, fue un revolucionario ${ }^{15}$. Con respecto a dichos señalamientos consideremos que la religiosidad chaconiana resulta indiscutible, fue reconocida por Chacón tanto en el diario que escribe durante sus días de la Guerra Civil española o en las descripciones que efectúa su biógrafa Zenaida Gutiérrez Vega, por solo mencionar dos ejemplos. Sin embargo, a nuestro juicio Chacón no evidenció atisbos de revolucionario. Centrado siempre en su trabajo, fue conciliador -no era propenso a la crítica- lo que no está en contradicción con sus deseos de transformar y dotar de mejores posibilidades el ámbito cultural cubano.

Los ejemplos mencionados demuestran cual fue el enfoque ofrecido, fundamentalmente, por la historiografía cubana a la figura de Chacón y Calvo. En una primera etapa, y desde una perspectiva generalizadora, el foco de atención se centró en su hispanoamericanismo. Con posterioridad se enfatizó en su concepción de neutralidad de la cultura y su papel durante la Guerra Civil Española. Este segundo tema, por razones obvias, ha despertado interés en España, aunque también se aprecia una nueva arista de investigación, como es el caso de su desempeño diplomático abordado en el artículo de Bruquetas de Castro. Pero, el estudio sobre su figura no se puede dar por agotado. Aún están por descubrir muchos de los documentos personales de Chacón y Calvo en los diferentes archivos y resulta evidente que no ha sido uno de los pensadores cubanos más analizados, aunque en los últimos años las diferentes publicaciones sobre su trayectoria ponen de manifiesto un renovado interés por su obra.

En nuestro caso, cabe resaltar que, además de las fuentes bibliográficas, ha sido imprescindible la consulta del archivo personal de José María Chacón y Calvo que obra en la Biblioteca Hispánica de la Agencia Española de Cooperación. La colección recoge cartas, anotaciones y documentos personales relativos a su estancia española. De extraordinaria utilidad nos ha resultado también otras fuentes primarias procedentes del fondo dedicado al pintor y diplomático Ramón Estalella (Madrid, 1893- Madrid, 1986) localizado en la Real Academia de la Historia, donde encontramos legajos que aportaron información valiosa especialmente en lo referente a la relación entre estos dos colegas, convertidos luego en amigos, y al trabajo en la sede diplomática. Por otro lado, las fuentes hemerográficas de la época nos ofrecieron la oportunidad de ampliar el quehacer cotidiano de Chacón. Fueron numerosas las noticias de prensa que recogieron las actividades a las que asistía 0

\footnotetext{
14 Ibídem, p. 319.

15 Ibídem, p. 320.
} 
participaba, lo cual resultó muy útil para definir los círculos que frecuentaba y la visibilidad que logró obtener en los medios españoles.

\section{2. ¿Diplomático e investigador? o ¿lnvestigador y diplomático?: Un mundo de relaciones}

La estancia española de Chacón y Calvo se inició en 1918 con motivo de su nombramiento como miembro del servicio exterior de su país. Hemos podido constatar este hecho a través de la nota verbal fechada el 11 de mayo de ese propio año, donde la Legación cubana informó al Ministerio de Estado español su designación o en el exequátur que otorga el beneplácito del Reino a Chacón y Calvo, según consta en el Archivo Nacional ${ }^{16}$. Chacón, que antes se había dedicado a la abogacía, denominó su nueva profesión como, "mi gris vida diplomática"17, de lo que inferimos que no fue la diplomacia un incentivo para él, sino el medio que le propició llevar a cabo un sin número de actividades paralelas que le permitieron complementar su formación. El paso por la península fue una premisa indispensable que contribuyó a su madurez intelectual. Corrobora el comentario anterior el hecho de que fue España su único destino diplomático; porque cuando regresó a su país en 1934 laboró en la Secretaría de Educación hasta 1935, como sabemos, al regresar al servicio exterior retomó su puesto en Madrid. Posteriormente en 1937 cuando vuelve a fungir como Director de Cultura lo hace ininterrumpidamente hasta 1945 que pasó a alternar la investigación con su desempeño como profesor titular de la Universidad Católica de Santo Tomás de Villanueva. Cuando en 1961 cerró esa casa de altos estudios se dedicó a la investigación de manera exclusiva.

A través de la prensa de la época es posible constatar como desde su llegada a España Chacón comenzó a darse a conocer en diversos círculos culturales. De ello da fe su participación en el curso de conferencias organizado por la sección de literatura del Ateneo de Madrid en febrero de 1919 ${ }^{18}$. A dicho evento, titulado "Figuras del Romancero", asistieron, entre otros, el académico, poeta y literato español Narciso Alonso Cortés; el escritor y periodista que en años posteriores se convertiría en presidente de la Segunda República, Manuel Azaña; el músico y compositor español Salvador Bacarisse Chinoria, el escritor Ramón Pérez de Ayala, el literato gallego Ramón María del Valle Inclán; el filósofo Miguel de Unamuno y el poeta y crítico mexicano Francisco A. de Icaza (México ,1863- Madrid, 1925), quien había llegado a España como segundo secretario de la legación de México en tiempos del Ministro Vicente Riva Palacio y, tras haber vuelto a su país, regresó de nuevo a España como exiliado después del estallido de la Revolución Mexicana ${ }^{19}$.

Asimismo fue constante la presencia de Chacón y Calvo en las reuniones que habitualmente se celebraban en la casa de la escritora Blanca de los Ríos Nostench

\footnotetext{
${ }^{16}$ Anexo 1 y 2.

${ }^{17}$ Archivo de la Agencia Española de Cooperación. Biblioteca Hispánica. Madrid. Carta de Chacón y Calvo a Fernando Ortiz, 16 de febrero de 1927.

${ }^{18}$ El Fígaro, 27 de enero de 1919, p. 14.

${ }^{19}$ AGUSTÍN SANCHÉZ, A. Entre la literatura y la diplomacia. La gestión de Vicente Riva Palacio en Madrid, 1886-1896. En: CAGIAO VILA, P. (comp.). Donde la política no alcanza. Madrid: Iberoamericana, 2018, p. 86.
} 
(Sevilla, 1862- Madrid, 1956) y su esposo Vicente Lámperez y Romeu (Madrid,1861Madrid, 1923), académico de la Historia, de Bellas Artes y director de la escuela de arquitectura. A estos encuentros, en los que se daban cita algunos amigos para tomar el té, solían asistir también la escritora Concha Espina o por el historiador americanista Antonio Ballesteros y Beretta (Roma, 1880-Pamplona, 1949) y su esposa, la escritora de origen colombiano Mercedes Gaibrois Riaño (París, 1891Madrid, 1960) ${ }^{20}$. Ya en su primer trabajo, Gutiérrez Vega ${ }^{21}$ hizo mención al hecho de que los esposos Ballesteros ofrecieron a Chacón una cálida acogida en Madrid que hemos podido corroborar, sobre todo a través de la prensa, por la frecuencia de eventos de diversa índole en los que coincidieron. El estrecho trato que mantuvo con ellos queda probado, además, por una carta que, en años posteriores, concretamente en 1928, el ensayista cubano Félix Lizaso envió a Chacón, comentándole que haría lo posible por publicar en la Habana los versos de Mercedes Gaibrois de Ballesteros que él mismo le había enviado, lo que nos confirma la relación de camaradería y amistad que se mantuvo en el tiempo ${ }^{22}$. De ahí que consideremos que la familia Ballesteros constituyó un importante vínculo de Chacón en su paso por la península y que los incluyamos entre sus contactos claves, porque contribuyeron a insertarlo en los ambientes culturales de entonces.

Otro buen amigo de José María Chacón fue el escritor y diplomático mexicano Alfonso Reyes, cuya relación es ya conocida gracias al epistolario entre ambos que publicó Gutiérrez Vega en 1976. Fue Reyes quien recibió a Chacón cuando arribó a Madrid e, incluso, Vega nos revela que durante cierto tiempo fueron vecinos en el mismo edificio de la calle General Pardiñas. Por otro lado, un trabajo reciente de Vélez Jiménez $z^{23}$, en el que, por cierto la autora ofrece una visión renovada acerca del ilustre intelectual mexicano, tampoco pasa por alto su amistad con Chacón. Y es que, efectivamente, podemos establecer entre ambos numerosos puntos de encuentro pues los dos fueron intelectuales que ejercieron la diplomacia, coincidieron temporalmente mientras ejercieron sus funciones en Madrid y disfrutaron de su pasión por las letras. Así, tal y como recoge una nota publicada en el rotativo madrileño La Voz el 9 de abril de 1924, cuando los amigos y admiradores de Alfonso Reyes organizaron en su honor un banquete de despedida porque abandonaba la capital de España para ser representante de su país en Argentina, José María Chacón y Calvo estuvo entre los asistentes. Junto al cubano, también estuvieron presentes el periodista y crítico literario Eduardo Gómez de Barquero; el poeta y crítico mexicano Francisco A. de Icaza y Manuel Azaña, a quienes ya hemos mencionado con anterioridad; los escritores Ramón Gómez de la Serna y Antonio Marichalar, entre otros. Años más tarde, en 1931, la publicación Monterrey, subtitulada como el Correo Literario de Alfonso Reyes ${ }^{24}$ daría a conocer el homenaje

\footnotetext{
20 La Época, 3 de abril de 1920; La Época 8 de marzo de 1921.

21 GUTIERREZ VEGA, Zenaida. José María Chacón y Calvo. Op. cit.

${ }^{22}<$ www.url.com $>$ https://archives.yales.edu. Carta del Félix Lizaso a Chacón y Calvo, 4 de julio de 1928.

${ }^{23}$ VÉLEZ JIMENEZ, Palmira. Alfonso Reyes como "puente" de americanismo. En: CAGIAO VILA, P. y ELÍAS CARO, J.E. (comps.). España como Escenario. Política y acción cultural de diplomáticos latinoamericanos (1880-1936). Colombia: Unimagdalena, 2018, pp. 367-404.

${ }^{24}$ Se trata de una revista que publicó Alfonso Reyes durante su estancia en Brasil y Argentina entre los años 1930-1937. Fue considerada un modo de estar en contacto e interacción con intelectuales y artistas de distintas procedencias.
} 
que organizó Chacón para celebrar el cincuenta aniversario del primer curso de filosofía impartido por el filósofo y pedagogo Enrique José Varona, referencia que permite constatar que la amistad entre ambos perduró en el tiempo y que sobrepasó el contexto madrileño. Por todo lo anterior, resulta lógico inferir que la relación entre Reyes y Chacón fue otro de los motivos que permitió al cubano, desde su llegada, insertarse con facilidad y excelentes referencias en la vida cultural de Madrid.

Con Ramón Menéndez Pidal comenzó a intercambiar correspondencia incluso antes de llegar a España en 1918, el entonces joven Chacón pidió consejo acerca de sus inquietudes intelectuales a quien consideró siempre un maestro. Con su arribo a Madrid se consolidó la amistad entre ambos por lo que no resulta extraña la participación del cubano en una actividad que se organizó en honor del erudito español en el Centro de Estudios Históricos ${ }^{25}$. Entre los asistentes a esta cita cabe destacar la presencia del filólogo Américo Castro; de los historiadores Ots Capdequí y Claudio Sánchez Albornoz; del escritor Pedro Salinas y del lingüista suizo Luis Gouchat, lo que nos permite apreciar cómo Chacón y Calvo se codeaba con la flor y nata de la intelectualidad del momento.

Por otro lado, hay constancia de la difusión que empezó a alcanzar su obra desde 1919 cuando sus escritos comenzaron a aparecer en, Raza Española. Revista de España y América. Dicha publicación surgió en enero de 1919 y culminó su tirada en 1930, fue precisamente Blanca de los Ríos su fundadora y directora, con quien, como se ha dicho, Chacón mantenía amistad personal e intelectual. El cubano participó de manera activa en la revista lo cual se demuestra a través de las diferentes facetas en que quedó registrado su nombre en la misma. Estuvo entre los escritores americanos que colaboraron de manera permanente en los diferentes números que vieron la luz, publicó trabajos de su autoría en sus páginas y sus obras se dieron a conocer a través de reseñas o comentarios de otros autores ${ }^{26}$.

La revista se circunscribe al americanismo de la época y específicamente a la vertiente más conservadora dentro de este, como revela su propio nombre, el marcado interés por resaltar los valores de la nación y trasmitir una regeneradora imagen del pasado. No es casual que Blanca de los Ríos, activista e ideóloga del hispanismo conservador, pusiera en marcha un proyecto como el Raza Española o que años más tarde con la llegada de Primo de Rivera al escenario político de la península fuera parte importante de la ideologización primorriverista ${ }^{27}$. Se debe mencionar, además, otro motivo de encuentro entre Blanca de los Ríos y Chacón y Calvo que estriba en su admiración por Marcelino Menéndez Pelayo. Es conocido que ella fue discípula y seguidora del filólogo español y que Chacón no ocultó su devoción y respeto por esta figura a lo largo de su carrera, incluso como veremos más adelante la prensa relacionó su obra con la de Menéndez Pelayo.

\footnotetext{
25 El Liberal, 7 de marzo de 1926.

26 A modo de ejemplo se puede mencionar entre los artículos de la autoría de Chacón: Duelos Literario. Don Francisco A. de Icaza, 1925; Cuba y España, 1926, y entre los cometarios de otros autores sobre sus obras destacamos: Las cien mejores poesías cubanas y literatura cubana de Luis Araujo en 1922.

27 CAGIAO, VILA. Pilar. En Prensa. Estudios Caldasianos: Ciencia y Nación. A 250 Años del Natalicio de Francisco José de Caldas. Cali, Colombia: Programa Editorial de la Universidad del Valle, 2018.
} 
Teniendo en cuenta los comentarios anteriores, nos cuestionamos acerca de cómo congeniaba Chacón y Calvo con la vertiente más recalcitrante del americanismo español y si solo participaba en dichos círculos por meras relaciones sociales o si estaría en consonancia con los términos defendidos desde esa variante del hispanoamericanismo. A nuestro juicio, el intelectual cubano poseía características que le permitieron sobrellevar de buen grado a este sector, como por ejemplo, su marcada religiosidad o su admiración y erudición sobre la cultura española. Por otro lado Chacón fue un hombre que comulgó con su trabajo y como se demuestra a lo largo de estas páginas sus amplias relaciones abarcaron a intelectuales de las más disímiles tendencias. De ahí que no consideremos posible identificarlo como defensor o participe absoluto del hispanoamericanismo más retrógrado, aunque sin duda compartía escenario e intereses de índole cultural con muchos de esos representantes.

En ese mismo año de 1919, José María Chacón y Calvo publicó Hermanito Menor, obra en la que, a través de un lenguaje sencillo, dejó plasmadas su sensibilidad y las emociones sentidas ante la belleza que descubrió a su paso por el paraje natural de los Pirineos. Además, en el II Congreso de Historia y Geografía Hispanoamericana del año 1921 que se celebró en Sevilla Chacón participó como delegado de su país, no como diplomático, con la ponencia titulada, "El primer poema escrito en Cuba". Posteriormente, en 1922 se editó, Las cien mejores poesías cubanas, texto que incluyó una antología poética de su país natal con semblanzas y opiniones de interés sobre los autores seleccionados. Precisamente sobre esta obra se hizo eco la revista Cosmópolis. Esta publicación mensual de literatura y crítica tuvo un marcado carácter modernista en correspondencia con el estilo de su fundador el guatemalteco Enrique Gómez Carrillo. Cosmópolis se centró en temáticas de índole cultural lo cual nos permite poner en evidencia la diversidad de las publicaciones que recibían el quehacer de Chacón y Calvo.

"Ningún crítico cubano, muerto Justo de Lara y callado por justo pesimismo Manuel Sanguily, con la autoridad de José María Chacón y Calvo para llevar a buen término trabajo de esta índole. Por su erudición, por su gusto seguro, por la posibilidad intachable de su inteligencia, el autor de "Hermanito Menor" ocupa lugar eminente en las letras castellanas contemporáneas"28.

Durante el año 1928 continuó su fructífera actividad de creación intelectual dando a la luz sus Ensayos de Literatura Española, que tuvieron excelente recepción en la prensa del momento. El diario La Epoca, por ejemplo, señaló las notables influencias de Menéndez Pelayo que podían percibirse en esta obra de Chacón:

"El Secretario de la Embajada de Cuba, don José María Chacón y Calvo, es quizás entre los discípulos de Menéndez y Pelayo el más pegado al humanismo que profesó el maestro. De transparente clásico, latino español, cordial, jugoso, amplio y compresivo, Chacón y Calvo es de los escritores y eruditos que se encuentran más de lleno en la corriente tradicional de nuestro pensamiento y de nuestras letras. No pertenece a la escuela de eruditos fríos que resuelven con método germánicos,... Chacón sabe combinar la crítica serena y perfectamente científica según los modelos actuales con el buen gusto, la fragancia, la simpatía,

${ }^{28}$ Cosmópolis, enero de 1922. 
la cordialidad y la humanidad que culmina en Menéndez Pelayo..."29.

Más adelante, 1934, La Nación haría referencia a la erudición contenida en un nuevo trabajo de Chacón -en esa ocasión de corte histórico-, titulado Un juez de Indias. Vida documental de José Francisco Heredia, verdadero ejemplo de una intensa labor de recopilación e investigación archivística.

Resulta palpable el seguimiento constante que dio la prensa española a la obra de Chacón y Calvo y la buena crítica de la que fue objeto en los diferentes medios, tanto de información general como especializada. Asimismo, dejó constancia de su activa participación en encuentros de índole cultural donde compartió escenario con figuras imprescindible de la intelectualidad española de su época, por lo que podemos afirmar que su paso por la España de entonces no pasó desapercibido y obtuvo pleno reconocimiento. Cuando en 1935 se transmitió por la prensa escrita la reapertura en España del Pen Club $^{30}$, no se dejó de mencionar la presencia de Chacón y Calvo entre extensa nómina de ensayistas, poetas, editores y novelistas que se reunieron con tal motivo. Además del cubano concurrieron personalidades notables de la intelectualidad del momento como Américo Castro, Claudio de la Torre, Pedro Salinas y Antonio Ballesteros.

El quehacer diplomático de Chacón y Calvo se desenvolvió en paralelo a un sinnúmero de labores relativas a la investigación, en algunos casos por encomiendas que le asignaron desde La Habana y en otros por su propia iniciativa. Su buena disposición en este tipo de iniciativas queda demostrada, por ejemplo en una carta enviada por José María Chacón y Calvo a Fernando Ortiz en 1927, donde refiere que ha efectuado búsquedas documentales para la Academia de Historia cubana en numerosos archivos españoles públicos (Archivo de Indias, en el Militar de Segovia, en el Administrativo de Alcalá de Henares, Archivo de la Real Academia de la Historia, Ministerio de la Marina), así como en otros de propiedad particular ${ }^{31}$. Y aunque, a través de un decreto presidencial cubano había sido designado como representante de la Academia de Historia para ejecutar dichas tareas, en esa misiva señalaba que desde hacía dos años no recibía el presupuesto para esos menesteres por lo que, para llevar a cabo el trabajo, debía utilizar sus ingresos personales. Esta actitud revela su extraordinario nivel de compromiso a la hora de cumplir con el encargo recibido, idéntico que el que adquirió cuando Joaquín Llaverías, destacado investigador y director del Archivo Nacional de Cuba solicitó su cooperación para buscar información en la península, con vistas a la futura formación del cuerpo de archiveros de la Isla ${ }^{32}$.

\footnotetext{
${ }^{29}$ La Época, 18 de abril 1928.

30 El Pen Club es una institución internacional fundada en Londres por Dawson Scott en el año 1921. Entre sus objetivos destacan el de fomentar la asociación y cooperación entre escritores. En España su primera aparición fue en el año 1922.

${ }^{31}$ Archivo de la Agencia Española de Cooperación. Biblioteca Hispánica. Madrid. Carta de Chacón y Calvo a Fernando Ortiz, 12 de abril de 1927.

${ }^{32}$ Archivo de la Agencia Española de Cooperación. Biblioteca Hispánica. Madrid. Carta de Joaquín Llaverías a Chacón y Calvo, s.f.
} 


\title{
2.1. Los vínculos de Chacón y Calvo con entidades culturales: la Institución Hispano Cubana de Cultura en Madrid y el Instituto Hispano Cubano de Sevilla
}

Chacón y Calvo fue el representante en Madrid de la Institución Hispano Cubana de Cultura $^{33}$, entidad fundada en 1926 por Fernando Ortiz. Su gestión favoreció los contactos con la elite intelectual española del momento, tal y como demuestra un fragmento de una carta suya a Ortiz:

\begin{abstract}
"Tardes pasadas recibí la visita del Sr. Castillejo, el insustituible secretario de la Junta de Ampliación de Estudios. Vino a verme en compañía de Américo Castro. A la Junta se le presentaba un serio conflicto: el viaje de Ortega, que parecía tan seguro; no podía ser este año. Me contó Castillejo que la Junta había recibido una comunicación de la Cultural en la que se proponían tres cursos... (¡Tres profesores en un año!)(¿No se acabará pronto el número de profesores respetables y disponibles de España? A la Argentina va uno solo. ¿No serán dos bastantes? Esta es la opinión íntima de muchos aquí, entre ellos Menéndez Pidal. Claro que lo otro tienen que alegrarles mucho pues así se demuestra el brío y la pujanza de la nueva Cultural"34.
\end{abstract}

Las líneas anteriores ponen de manifiesto la complicidad existente entre los dos cubanos y cómo Chacón y Calvo, quien mantenía al tanto a Ortiz de todo lo que acontecía en el movimiento cultural de la península, emitía sus juicios en un ambiente de plena confianza. Incluso, en más de una ocasión intentó armonizar las opiniones de Fernando Ortiz y los intelectuales españoles.

En otra oportunidad, y esta vez relatada en una carta de sentido contrario de La Habana a Madrid, Ortiz solicitó a Chacón gestiones de diversa índole con el propósito de mantener la constancia y la asiduidad de ponentes de calidad en la Hispano Cubana. Así lo manifestaba su presidente:

"Nos escribe D. Luis de Zulueta con excusas de no poder comprometerse a venir
en diciembre, como esperábamos, y teniendo aquí a D. Pedro Corominas en
noviembre, y a Salvador Maradiaga en marzo-abril, necesitamos otro
conferenciante en el periodo que mediara entre ambos. Ese conferenciante, que
nos salvaría la situación, podría ser el mismo Zulueta o Ramón Pérez de Ayala, o
Eugenio d'Ors o Pedro Saínz Rodríguez. Le ruego con mucho encarecimiento que
haga las gestiones que crea del caso cerca de ellos, tan pronto como le sea
posible, a fin de resolver nosotros con vistas a sus informes..."

Esta misiva corrobora de modo fehaciente los malabares que Chacón y Calvo debía realizar desde la capital de España para mantener el nivel de los conferenciantes y para hacer coincidir la agenda de la entidad cubana con la de los intelectuales españoles. En otro orden de cosas, se debe tener en cuenta que Ortiz

\footnotetext{
${ }^{33}$ NARANJO OROVIO, Consuelo y SAMPER, Miguel A. Fernando Ortiz y las Relaciones Científicas Hispano-Cubanas, 1900-1940. Revista de Indias. 2000, vol. LX, n. 219, pp. 477-503.

${ }^{34}$ Archivo de la Agencia Española de Cooperación. Biblioteca Hispánica. Madrid. Carta de Chacón y Calvo a Fernando Ortiz, 6 de julio de 1927.

35 Disponible en <https://brbl-dl.library.yale.edu.Carta> de Fernando Ortiz a Chacón y Calvo. La Habana, 29 de agosto de 1930.
} 
dedicó parte de su quehacer a interpretar e indagar en los diferentes elementos que componen la identidad y la historia de su país. Sobradamente conocida es la polémica que sostuvo con Rafael de Altamira como consecuencia de los discursos que este pronunció en la Isla durante su estancia en $1910^{36}$. Recordemos que Fernando Ortiz se desenvolvió en una joven república que había abandonado su estatus de colonia española en 1898 e intentaba redefinir sus relaciones con la antigua metrópoli y adecuar sus nuevos vínculos con Estados Unidos. De ahí que algunas de las referencias del alicantino, tales como, "comunidad histórica" o "raza común", fueran valoradas por Ortiz de connotación colonial y despertaran la polémica porque, en su opinión, el acercamiento con España debía centrarse en la cultura $^{37}$. No obstante, aunque el intelectual cubano no coincidía con el modelo americanista propuesto por Altamira, siempre demostró respeto por la cultura española y la creación de la Hispano Cubana fue un ejemplo fehaciente de ello.

Bastantes años más tarde, en 1928, Fernando Ortiz visitó España y a raíz de una entrevista que apareció en la prensa madrileña es posible apreciar el balance que realizó sobre dicha institución y su valoración sobre la temática americanista.

\begin{abstract}
"El Instituto Hispano Cubano de Cultura lleva dos años en funciones. Y en estos dos años ha realizado una labor fecunda, gracias principalmente a las personalidades que nos han brindado su concurso. Nuestra institución es esencialmente cubana, hágalo constar así... La obra hispanista debe realizarse calladamente. No es labor que debe ser realizada con exteriorizaciones, que muchas veces resultan forzadas. Nuestra labor, por encima de todo, es cultural. El día que logremos llegar a una cultura única se habrá realizado una fecunda labor hispanista. Para mí, el elemento cultural es superior a todos los demás elementos. Cuando se trata de cuestiones hispanoamericanas surge enseguida la palabra "raza". Esto constituye una seria equivocación. En América no es conveniente hablar de raza, además creo seriamente que no existe la raza hispana. Y mucho menos en América donde se entremezclan razas distintas"38.
\end{abstract}

Es evidente que para Fernando Ortiz quien en la entrevista se desliga claramente del manido concepto de "raza", la esencia de la institución que dirigía radicaba expresamente en la cultura como elemento capaz de transformar e integrar diferentes realidades. Por ello, el deseo del polígrafo cubano de tomar decisiones acerca de la actividades que tendrían lugar en la entidad habanera teniendo sobre todo en consideración el contexto de su país y no las condiciones españolas provocó que, a nuestro juicio, Chacón y Calvo fuese muy cuidadoso y prudente en el desempeño de su función como representante de la entidad cubana en Madrid.

No se debe obviar que el rol intelectual desplegado por Chacón facilitó su trabajo diplomático. El servicio exterior se encarga, entre otras tareas, de mantener y fomentar canales de comunicación entre los Estados y, en su caso particular, el carácter polifacético de su labor como agente cultural favoreció sobremanera el

\footnotetext{
${ }^{36}$ ALTAMIRA CREVEA, Rafael. Mi viaje a América. Oviedo: Universidad de Oviedo, 1910, (reedición 2007), pp. 215-258.

${ }^{37}$ ORTIZ, Fernando. La Reconquista de América. Reflexiones sobre el pan hispanismo. París: Sociedad de Ediciones Literarias, 1910.
}

38 El Heraldo de Madrid, 1928, p. 19. 
establecimiento de los contactos institucionales. Sus cartas de presentación como hombre de letras otorgaron prestigio y contribuyeron a su desempeño oficial. El campo de la investigación en el que se desenvolvió complementó sus labores diplomáticas y ambas funciones le capacitaron sobradamente para establecer las redes de contacto que mantuvo a lo largo de su trayectoria.

Diez años después del inicio de su estancia española, con una agenda sumamente repleta no sólo por sus compromisos, sino también por su infatigable labor en los diferentes terrenos en los que estaba implicado, José María fue testigoy en buena medida protagonista- de la apertura de un nuevo centro hispanoamericanista, el Instituto Hispano Cubano de Sevilla, creado en $1928^{39}$.

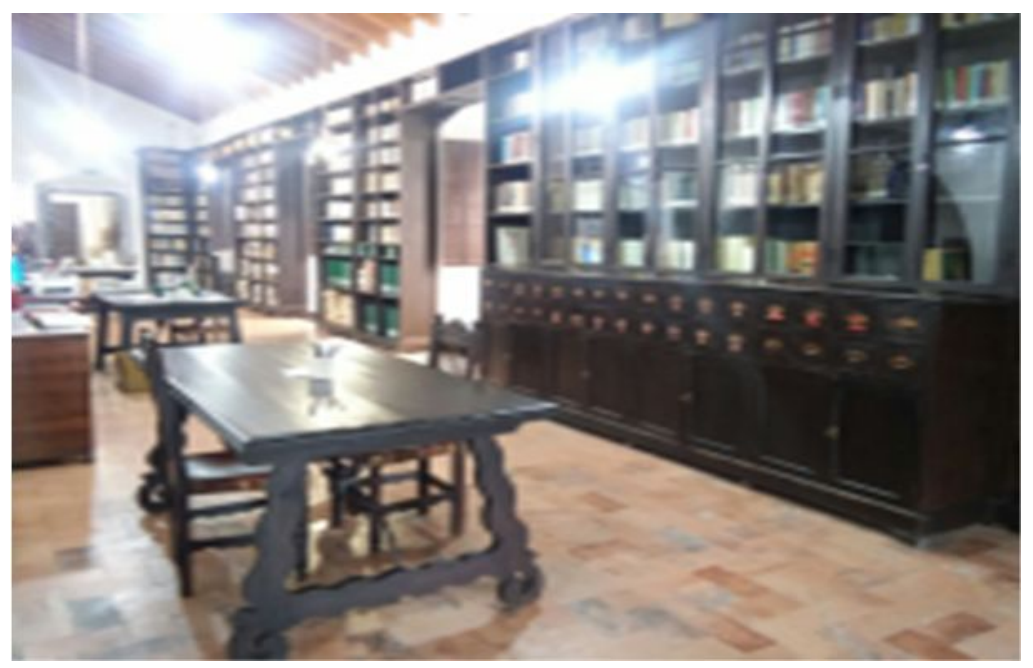

Fig. 2: Instituto Hispano Cubano de Sevilla. Fuente: Archivo Personal de la autora.

La institución sevillana, que puede considerarse como uno de los resultados del americanismo español que emergió en España entre las últimas décadas del siglo $\mathrm{XIX}$ y el primer tercio del $X X^{40}$, vio la luz gracias al empeño del cubano Rafael Gonzales Abreu y sus amigos de juventud José de Castro y de Castro y Juan Díaz del Moral. También resultó importante en el quehacer de dicha organización la labor indispensable de Ots Capdequí. La nueva entidad otorgó prioridad a la investigación del período colonial con especial énfasis en los estudios cubanos. Entre sus objetivos generales cabe destacar: mejorar las condiciones prácticas de trabajo para los investigadores en los archivos, editar publicaciones históricas, conformar una biblioteca con temas americanistas y convertirse en un ente activo que promoviera el acercamiento con el continente americano. El Instituto Hispano Cubano tuvo su etapa de esplendor entre 1930 y 1935 porque fue durante esos años cuando comenzaron a dar frutos las ideas iniciales de sus mentores y alcanzó mayor visibilidad en el ámbito cultural.

\footnotetext{
${ }^{39}$ Sobre este tema se puede consultar GUILLAMA CAMBA, Ruxandra. Las Redes de la Cultura: El Instituto Hispano-Cubano de Sevilla (1928-1939). ¿Una apuesta por la transformación del americanismo? Sevilla: Instituto Hispano Cubano de Historia de América, 2018, pp. 11-81.

40 Sociedad Colombina Onubense (1880), Unión Iberoamericana (1885), Real Academia Hispanoamericana de Ciencias y Artes de Cádiz (1909), Centro de Cultura Hispanoamericana de Madrid (1910), Casa América de Barcelona (1910).
} 
Por sus labores de investigación histórica, José María Chacón y Calvo era un asiduo visitante de la ciudad de Sevilla donde frecuentaba el Archivo de Indias, por lo que no cabe duda de que durante esas estancias entró en contacto con los fundadores del Hispano Cubano. De hecho existe constancia de que la relación con su paisano, Rafael González Abreu, fue anterior a 1928, fecha de la creación del Instituto Hispano Cubano. Además, en la ciudad hispalense existía una oficina consular cubana que mantenía lógicos contactos con la sede diplomática de Madrid. Fue así que la doble condición de Chacón y Calvo, como diplomático y como investigador, facilitó la colaboración con la nueva entidad americanista justo en vísperas de la celebración de la Exposición Iberoamericana de Sevilla. Precisamente, en 1928, con motivo de la organización de esa muestra, el periódico habanero Diario de la Marina publicó una fotografía que reflejaba la visita de varias personalidades a las obras del Pabellón de Cuba y donde aparecían, Ortiz, entonces de visita en España, el Cónsul de Cuba en Sevilla, Rafael González Abreu y José María Chacón y Calvo. Por su parte, en noviembre de ese mismo año, el periódico hispalense El Liberal se hizo eco de la recepción que tuvo lugar en el ayuntamiento de Sevilla en honor a Fernando Ortiz y González Abreu, a la que Chacón y Calvo acudió como representante de la Embajada cubana en Madrid. La presencia de Ortiz en ambos actos no puede pasar desapercibida y nos inclina a pensar que fue el propio Chacón quien facilitó el contacto del polígrafo cubano con el Instituto Hispano Cubano con el fin de propiciar sus posibilidades de colaboración con esta entidad. De hecho, durante estos encuentros, el propio Ortiz manifestó:

\begin{abstract}
"Yo creo representar... en este acto el alma de Cuba que viene a compartir un acto de afinidad espiritual y puedo decir, como presidente de la Sociedad Económica que representa el pasado; como Presidente de la Academia de Historia, que representa el presente en las actividades culturales, y como fundador de la Asociación Hispano Cubana, que aspira a representar una esperanza sólida en el porvenir, que esta obra de González Abreu se divulgará en las actividades hispano cubanas"41.
\end{abstract}

Los documentos consultados en el archivo del Hispano Cubano confirman sobradamente la relación entre Chacón y los miembros de esta entidad. Los mensajes que intercambió con unos y otros reflejan la relación de cercanía y afecto que mantuvo con ellos, tal y como reflejan muchas de las epístolas que les dirigió. Paulatinamente estos contactos se fueron afianzado hasta que, en marzo de 1934, la institución solicitó la colaboración de Chacón para que se encargara de la dirección de algunas de las ediciones críticas relacionas con las fuentes narrativas más importantes de la historia de la colonización española en América que iba a emprender la institución sevillana. Asimismo, al año siguiente, cuando ya el diplomático cubano había regresado a su país y se encontraba al frente de la Secretaría de Educación cubana, la entidad hispalense solicitó el apoyo de Chacón y Calvo para que desde el importante puesto que ocupaba en la Habana promoviese la edición de los fondos cubanos existentes en el Archivo de Indias y la donación de fondos bibliográficos al Hispano Cubano. Por otro lado, en el mes de octubre de ese mismo año 1935, su director técnico, Ots Capdequí, agradecería la distinción otorgada por el gobierno cubano- la Orden Carlos Manuel de Céspedes- que

\footnotetext{
${ }^{41}$ El Liberal, noviembre de 1928.
} 
creemos fue propuesta por el propio Chacón quien, desde la Habana, continuaba manteniendo una fluida relación con el Instituto sevillano que le permitía estar al tanto del desempeño destacado de Capdequí como investigador americanista.

Todo lo anterior nos dibuja el activo intercambio de relaciones intelectuales sostenido a lo largo del tiempo que José María Chacón y Calvo mantuvo durante su estancia española.

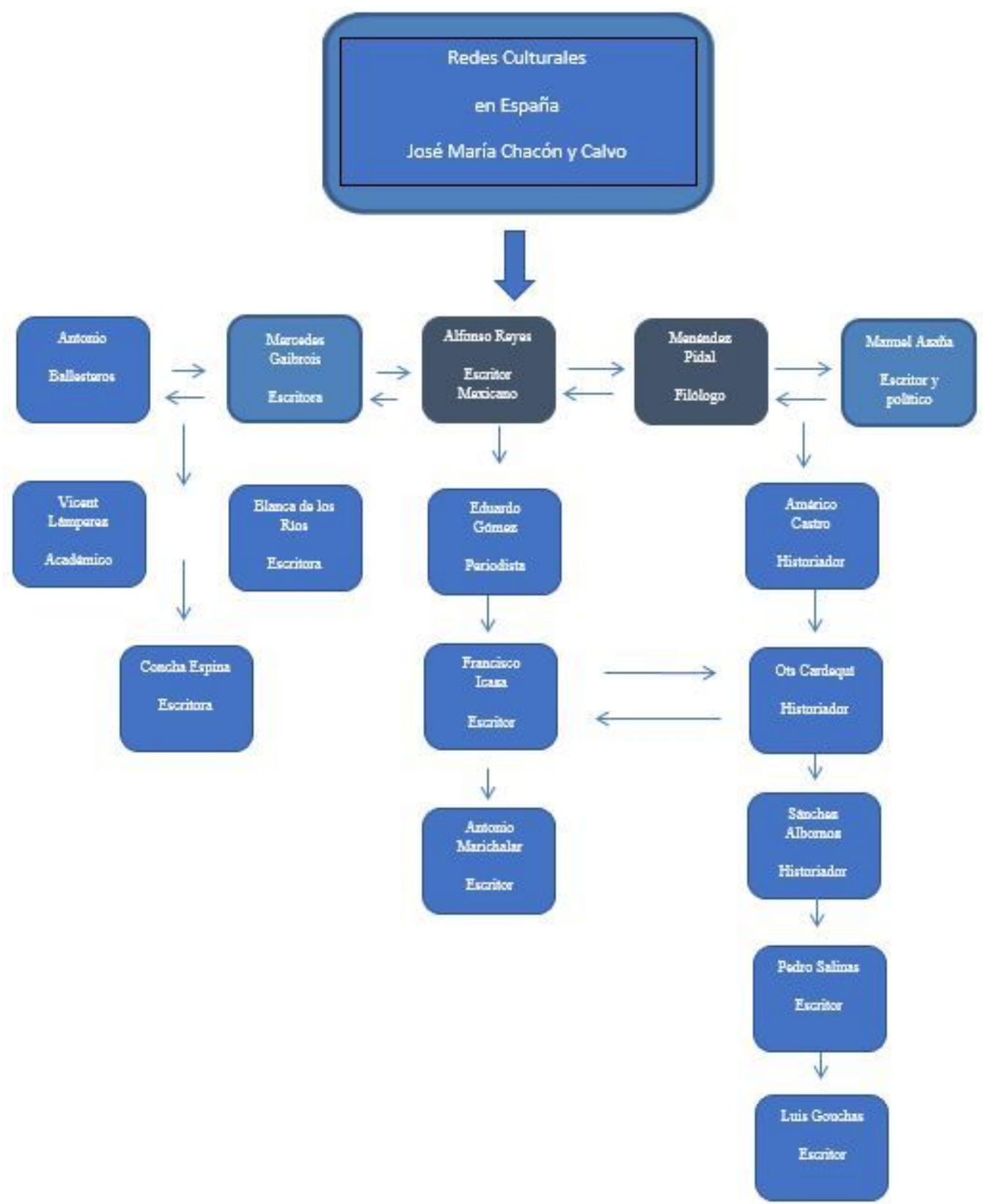

Fig. 3: Relaciones intelectuales que José María Chacón y Calvo mantuvo durante su estancia española. Fuente: Elaboración propia.

Como puede observarse, el esquema anterior representa una síntesis resumida de algunas de las relaciones establecidas por Chacón y Calvo en la que somos conscientes de que existieron otros importantes intelectuales con los que mantuvo contactos. Sin embargo, hemos optado por mencionar, exclusivamente, los nombres 
de aquellos que reiteradamente aparecen en las fuentes consultadas. Destacamos a Menéndez Pidal y Alfonso Reyes por tratarse de figuras con las que Chacón estableció relación por correspondencia antes de arribar a España y que, por tanto, sin duda contribuyeron a allanar el camino del cubano recién llegado en la primera etapa. Además, creemos estar en condiciones de afirmar que Mercedes Gaibrois y Antonio Ballesteros fueron determinantes para adentrar a Chacón en determinados círculos intelectuales debido a la buena relación existente entre ellos. De hecho, fue más que frecuente su coincidencia en actividades culturales de pequeño formato en las que el matrimonio invitaba a Chacón para presentarlo entre sus allegados. Por otro lado, abundan las noticias de prensa en las que el nombre de José María Chacón aparece junto al de las personas mentadas en distintos escenarios (actos, congresos o reuniones), en muchos casos de índole americanista.

Por otro lado, muchos de los personajes próximos a Chacón se deducen del análisis de su correspondencia personal que revela que estableció redes de interés e influencia en el ámbito cultural en la España de la época.

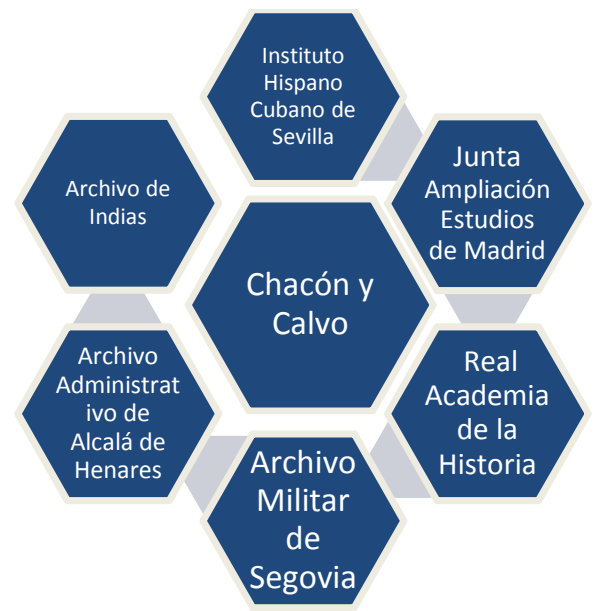

Fig. 4: redes de interés e influencia de Chacón en el ámbito cultural en la España de la época.

Fuente: Elaboración propia ${ }^{42}$

\subsection{Mensajes entre líneas}

Acceder a la correspondencia original de una figura histórica es un privilegio que suele aportarnos detalles de interés. Leer entre líneas para detectar matices y descubrir mensajes, imperceptibles por otras vías, constituye una oportunidad inestimable que concede la cercanía y la intimidad de las cartas personales. Una breve panorámica del archivo de Chacón y Calvo custodiado en la biblioteca de la Agencia Española de Cooperación revela amistades personales, intereses o rasgos de la personalidad del investigador cubano. El material, como era de esperar, se centra en su estancia española porque recoge su biblioteca y los escritos que

\footnotetext{
42 La representación anterior es una muestra resumida de algunas de las instituciones con las que Chacón y Calvo mantuvo contactos de trabajo durante su estancia en España. Estos nombres se han seleccionado a partir de lo encontrado en las fuentes hemerográficas y en la correspondencia depositada en los archivos, pero consideramos que se trata sólo de una muestra que no damos por definitiva. El acercamiento de Chacón a dichas entidades posibilitó adentrarse en los archivos españoles y abrir una puerta de visibilidad hacia posibles contactos personales.
} 
acumuló durante su residencia en Madrid.

La documentación revisada hasta el momento ofrece copias de muchas de las cartas oficiales que envió a sus colegas y nos invita a pensar que el arte de escribir misivas de puño y letra, tan en desuso en la actualidad, representó una de las pasiones y pasatiempos de Chacón. Su posición y responsabilidad le permitían emplear la mecanografía como vía idónea para comunicarse, sin embargo sus cartas más personales las escribió a mano. Por otro lado, en muchas de las respuestas que recibió a sus epístolas se detecta la admiración y confianza que despertó en sus más allegados. Así, tras el análisis de una buena parte de este fondo, se deduce, por ejemplo, la afectuosa relación que mantenía con la antropóloga cubana Lydia Cabrera a través de la correspondencia. Las misivas de Cabrera se caracterizaron por un lenguaje locuaz, directo y simpático. Se refería a Chacón con la frase, querido amigo y solía comentarle su quehacer en París. También muestra constante preocupación por la realidad cubana, aunque la discreción y abstención política de Chacón lo hacían en ocasiones no emitir juicios de valor sobre la cuestión.

"De nuestra pobrecita tierra mejor no hablamos. Hace más de un año que te dije que no teníamos esperanzas de nada: el tiempo me ha dado la razón. Quizás tu interpretaste mal un párrafo de mi carta y me diste un "sole"...precisamente para no asumir ante mi propia conciencia una actitud que ciertas circunstancias me impondrían, no quisiera volver allá en mucho tiempo...por otro lado no tengo fe en veteranos, en patriotas para quienes la patria ha sido siempre motivo de ingresos y de parrafadas de mal gusto. Mi corazón entero está con el pueblo resignado y descreído ${ }^{43 "}$.

Sostenida en el tiempo fue la relación que sostuvo con José Luis Galbe (Pepe Luis) a quien dedicara su obra, Hermanito Menor. Fueron frecuentes los viajes de Chacón a Zaragoza para pasar temporadas con la familia Galbe. Se convirtió en una referencia para el joven Pepe Luis y es palpable una entrañable amistad entre ambos. Como consecuencia de la Guerra Civil Galbe emigró primero a Francia donde fue hecho prisionero y finalmente en 1940 se marchó a la Habana con la ayuda de Chacón y Calvo. En la mayor de las Antillas comenzó su vida como exiliado hasta su fallecimiento en 1985.

Por su parte, también la correspondencia que se custodia en la Real Academia de la Historia, ofrece detalles sobre otros vínculos que sostuvo Chacón y Calvo. Nos referimos a su amistad con Ramón Estalella, diplomático cubano que compartió su trabajo con otra tarea que lo apasionaba, la pintura. Ambos realizaron una destacada labor en el servicio exterior auxiliados con las herramientas y posibilidades que les ofreció su verdadera vocación. Estalella perteneció a una familia de catalanes que emigraron a Cuba. Con la llegada del siglo xx los Estalella establecieron su residencia en España, pero asumieron la nacionalidad cubana. Siguiendo los pasos de su padre, que fue cónsul de Cuba en Barcelona, después de realizar estudios en derecho y pintura Ramón Estalella viajó a la Habana para iniciarse en la carrera

\footnotetext{
${ }^{43}$ Archivo de la Agencia Española de Cooperación. Biblioteca Hispánica. Madrid. Carta de Lydia Cabrera a José María Chacón y Calvo, 28 de febrero de 1932.
} 
diplomática. Cuando pasó a trabajar en la sede en Madrid coincidió con Chacón y entre ambos surgió una entrañable amistad. Estalella representó a Chacón en España cuando este regresó a Cuba lo cual significó en términos legales asumir contratos de arrendamientos, representarlo en editoriales, tomar posesión de sus bienes y administrarlos. Incluso en 1970 Estalella recibe una carta donde se le comunicó que fue nombrado como albacea en el testamento de su compañero, fallecido en 1969.

Innumerables misivas revelan la preocupación de Chacón por su amigo en situaciones convulsas, por ejemplo al quedar Estalella al frente de la misión diplomática durante la Guerra Civil, cuando fue expulsado del servicio exterior por Batista, al ser trasladado a Portugal y Chile o en los años sesenta cuando volvió a ser retirado el Ministerio de Relaciones Exteriores por el gobierno de Fidel Castro.

"Acabo de recibir hace unas horas tu carta del 25 de diciembre. Me ha emocionado hondamente. No tienes que pensar que el traslado a Lisboa signifique otra cosa que lo que arriba dejo consignado, la prueba has de tenerla en breve. No me olvido de tu un momento y todos mis amigos, que también son los tuyos, están a tu lado con la más viva devoción" ${ }^{4}$.

José María Chacón y Calvo mantuvo una comunicación continua con su "amigo fraternal" y realizó disímiles gestiones en la Habana para ayudar a resolver de modo positivo los inconvenientes que se suscitaron en la carrera profesional de Estalella. Ambos se dieron apoyo y aliento en momentos complicados de sus vidas. Se realizaron confidencias y solicitaron el consejo uno del otro. Ejemplo de ello lo encontramos en las palabras de Estalella en 1937.

\begin{abstract}
"Me dijeron que volvías a Madrid y tuve la alegría que puedes suponer al pensar en recuperar al amigo fraternal y al consejero siempre cariñoso y oportuno, al que tanto echo de menos en los innumerables momentos difíciles y problemas que se plantean continuamente, de cuya solución delicada, puede incluso depender la situación de un semejante. Hace tiempo que no me expresas tú opinión, que tanto te agradezco siempre, así como el que me informes del ambiente que tengo en mi patria, en la Secretaría de Estado y en las personas con quienes hables de mi actuación, pues las cartas que recibo son de gente agradecida por lo general, que no representan el verdadero ambiente que tiene en Cuba nuestra embajada" ${ }^{\prime 4}$.
\end{abstract}

\title{
3. La concepción de cultura en el ideario de Chacón y Calvo
}

En el pensamiento de Chacón y Calvo, que, en términos generales, fue un conservador apegado a las tradiciones familiares y religiosas alejado de posicionamientos políticos, se detecta con claridad el papel fundamental que otorgó a la cultura en el transcurso de su vida. No deja de sorprender el amplio y multifacético enfoque plasmado en su interpretación del ámbito cultural. Y, en este sentido, resulta imprescindible confrontar algunas de sus ideas encaradas, por

\footnotetext{
44 Archivo de la Real Academia de la Historia. Depósito Ramón Estalella. Carta de José María Chacón y Calvo a Ramón Estalella, febrero, 1942.

${ }^{45}$ Archivo de la Real Academia de la Historia. Depósito de Ramón Estalella. Carta de Ramón Estalella a José María Chacón y Calvo, 1937.
} 
diferentes caminos, hacia el objetivo de configurar un hispanoamericanismo de tinte cultural.

\section{1. ¿Neutralidad de la Cultura?}

La investigadora cubana Malena Balboa ${ }^{46}$ señaló, de manera rotunda, que una de las tesis que más polémicas han suscitado en la historiografía cubana en el terreno de las ideas es la de "neutralidad de la cultura" de Chacón y Calvo. A nuestro juicio de manera acertada, esta autora fundamenta el por qué de la posición de Chacón. Por su parte, el destacado intelectual, Cintio Vitier ${ }^{47}$ opinó que la teoría chaconiana representó un modo de hacer confluir intelectuales de diferentes tendencias. Igualmente, Salvador Bueno ${ }^{48}$ hizo mención a dicha tesis, sin adentrarse en explicaciones, mientras que Nuria Gregori Torada, en la presentación de Diario Íntimo de la Revolución Española ${ }^{49}$, aludió al hecho de que Chacón fue defensor de la neutralidad de la cultura.

Resulta evidente que el modo en que Chacón definió su relación con la cultura despertó sumo interés en la historiografía cubana posterior a 1959. Comprensible, además, si se tiene en cuenta que en el contexto de la Revolución no quedó mucho espacio para las posiciones neutrales. La politización de la vida diaria estuvo marcada por la máxima de "tomar partido" y el ámbito de la cultura no fue la excepción. Recordemos, por solo mencionar un ejemplo, sin pretender entrar en detalles porque no es el objetivo de este análisis, la célebre frase pronunciada en 1961 por Fidel Castro aseverando que "dentro de la revolución todo, contra la Revolución nada". Ante esta premisa, aunque la postura de Chacón despertó interés, no podía ser alabada durante los primeros años de cambios revolucionarios efectuados en la isla caribeña. Además, si bien el hispanista cubano se desempeñó en roles de responsabilidad con anterioridad a 1959, la década del sesenta coincidió con la última etapa de su vida, momento en que, ya delicado de salud, estuvo totalmente volcado en la investigación. No se incorporó de manera activa al proceso iniciado en Cuba, lo cual nos inclina a opinar que, al menos durante un período, fue considerado como un hombre de la "República" y no de la "Revolución". Para comprender el planteamiento anterior debe tenerse en cuenta que, tras el cincuenta y nueve, la historiografía cubana tuvo un marcado carácter nacionalista y no escatimó esfuerzos para denunciar las vicisitudes del pasado republicano. Aunque a Chacón y Clavo no se le asocia a corruptelas de ninguna índole y es reconocido como un pensador de prestigio entre los círculos intelectuales, no parece casual que se valore su figura con más asiduidad en el ya iniciado siglo XXI.

Tras la acotación anterior, parece oportuno explicar por qué, a nuestro juicio, Chacón define como necesaria la neutralidad de la cultura y qué fue lo que él entendió precisamente por dicha concepción. Por su temperamento claramente partidario del diálogo -en buena medida porque conoció las crisis políticas

\footnotetext{
${ }^{46}$ BALBOA PEREIRA P, Malena. Hacia una zona de convivencia de la cultura. Op. cit.

47 VITIER, Cintio. José María Chacón y Calvo. Algunos recuerdos. Seis visiones y un recuerdo sobre José María Chacón. La Habana: Editorial Creat, 1995.

48 BUENO, Salvador. En Memoria de José María Chacón y Calvo. Revista de la Biblioteca Nacional José Martí [en línea]. Ene./abr. 1970, año 61, vol. XII, n. 1. Disponible en <http://librinsula.bnjm.cu>. 49 GREGORI TORADA, Nuria. José María Chacón y Calvo. Op. cit.
} 
generadas en la Cuba de los años treinta con el gobierno de Gerardo Machado- la decisión de situarlo en 1934 al frente de la Dirección de Cultura aspiró a contar para ese cargo con una personalidad lúcida, respetada y alejada de cualquier clientelismo político. Asumió su puesto desde la responsabilidad cívica del trabajo diario con el objetivo de lograr un área neutral aislada de las rencillas políticas. Sobre este asunto, en 1931 expresaría que:

"... la cultura es zona de convivencia nacional. En esta esfera pueden coincidir las más diversas ideologías, siempre que las mismas afirmen los postulados de la cubanidad y los valores de una cultura espiritual y libre" (El Mundo, 1939, p. 11) ${ }^{50}$.

Más adelante, y como indicador de que el tema de la neutralidad fue una constante en el pensamiento del intelectual cubano, reiteraría que:

"Es necesario hacer ver más a los variados sectores de la vida cubana que hay una esfera de natural convivencia: la de la cultura. En esta deben colaborar los más variados factores de la vida nacional, las ideas no deben ser nunca una causa de esencial separación, solo debe serlo la conducta"51.

Ambas aseveraciones, pronunciadas con una diferencia en el tiempo de casi veinte años, nos conducen a afirmar que Chacón y Calvo interpretó la cultura como sinónimo de libertad y como un área proclive al entendimiento, cooperación y encuentro. Constantemente expresó la necesidad de lograr un escenario a favor del diálogo y alejado de las intríngulis de la política. A lo largo de su trayectoria, como se ha demostrado, interactuó con intelectuales de diversa filiación ideológica, lo que no constituyó un lastre para su trabajo. De ahí que respaldara la idea de que la cultura puede ser una zona de confluencia neutral no condicionada por posturas partidistas.

En relación a como desempeñó su cometido en la Secretaría de Educación se debe mencionar que reclamó medidas de gran calado en la esfera de la cultura. Chacón se mantuvo en ese cargo hasta 1944 aunque en ese intervalo de tiempo (1934-1944) intentó dejar dicha responsabilidad en varias ocasiones por las incomprensiones que encontró a su paso. De hecho, en 1935, renunció por no mostrarse de acuerdo con la huelga de marzo contra el gobierno ${ }^{52}$. Fue entonces sustituido por la poetisa Dulce María Borrego quien le escribió para comentarle las vicisitudes con las que se encontró en su nueva responsabilidad. El pasaje de la carta de Borrego demuestra el respeto y admiración que por Chacón sentían muchos de sus coetáneos, así como el empedrado camino de la burocracia que colmaba a las instituciones oficiales en la Cuba de los años treinta.

"Lizaso me ayuda...con afecto a salir de estas hostilidades y torturas, y siempre crece mi estimación por él. Nosotros dos tenemos tácitamente contraído un solemne compromiso con la cultura patria...hasta el día dichoso en que podamos de nuevo verlo a usted de regreso a esta Dirección, para desarrollar desde ella sus magníficos planes culturales. Para mí sería el único precio que pagaría, el sacrificio que hace mi corazón y mi conciencia, a la que tengo puesta una sonrisa

\footnotetext{
50 Tomado de BALBOA PEREIRA P, Malena. Hacia una zona de convivencia de la cultura. Op. cit., p. 82.

51 Diario de la Marina, 7 de octubre de 1958, p. 4.

52 Huelga General de marzo de 1935 para derrocar al régimen de Batista-Caffery - Mendieta.
} 
de discreción y de prudencia que a las veces amenaza romperse y dejarme el cuerpo entero expuesto al blanco enrevesado de los ruines de espíritu"53.

Es posible conocer la opinión del propio Chacón sobre la situación en la Secretaría de Educación a través de un fragmento de una carta que envió a su amigo y colega Ramón Estalella:

"No te ocultaré que en la Dirección de Cultura no he encontrado el concurso oficial que esperaba, y me encuentro casi en absoluto aislamiento. Por eso te hablaba de mi indecisión o de mi estado de ánimo verdaderamente desencantado. Encuentro en Cuba magníficas posibilidades y tengo grades esperanzas de que haya ahora una verdadera renovación universitaria. Con relación a esto quizá se me ofrezca alguna coyuntura propicia y pueda dar a mi vida un rumbo íntimamente de acuerdo con mi verdadera vocación" 54 .

Esta misiva que Chacón y Calvó envió a Estalella, fechada en abril de 1937, fue escrita en plena Guerra Civil española, precisamente cuando el Encargado de Negocios de Cuba en España, Manuel Pichardo, acababa de fallecer. Ambos acontecimientos motivaron que Chacón le comunicara su disposición de retornar a Madrid para contribuir en el trabajo de la Embajada en momentos tan difíciles, aunque esto no se materializó. Por otro lado, no escatimó palabras para confesar su decepción con lo que sucedía en los círculos oficiales cubanos. A pesar de su disponibilidad y las esperanzas que albergaba sobre el potencial universitario, es evidente que contaba con muy poca colaboración para ejecutar su responsabilidad. Expresó su disgusto con lo que acontecía en la Dirección de Cultura en disímiles ocasiones. Los obstáculos económicos y burocráticos que se interponían al trabajo creador explican el rechazo que Chacón experimentó hacia la política toda vez que la consideró un obstáculo para la cultura.

Tampoco se puede olvidar que, durante un tiempo, fue testigo directo de una etapa de la Guerra Civil española, donde experimentó disímiles experiencias de las que dijo:

"Cada vez me he ido sintiendo más triste. La radio daba noticas noticias de magnitud insospechada. Toda España era llama y sangre. ${ }^{55} \ldots$.. Cuantas penalidades, cuantos sufrimientos físicos nos aguardan todavía! Y nada podré decir de la desolación, de las desolaciones en que vivimos en estos días tremendos". ${ }^{56}$

En ese contexto trató de ayudar a muchas figuras prominentes y a varios amigos a salir de España aprovechando su posición de diplomático. La cercanía con que vivió la guerra también incentivó su postura de neutralidad queriendo desprenderse de posiciones ideológicas que desvirtuaran el trabajo creador. Así, Chacón se refugió en el espacio en el que sentía más cómodo, desde donde creía que podía aportar

\footnotetext{
${ }^{53}$ Archivo de la Agencia Española de Cooperación. Biblioteca Hispánica. Madrid. Fondo Chacón y Calvo. Carta de Dulce María Borrego a José María Chacón, 21 de abril de 1936.

${ }^{54}$ Archivo de la Real Academia de la Historia. Depósito Ramón Estalella. Carta de José María Chacón y Calvo a Ramón Estalella, 22 de abril de 1937.

55 GREGORI TORADA, Nuria. José María Chacón y Calvo. Op. cit., p. 37.

56 Idídem, p. 141.
} 
más y ser útil. De ahí que no escatimase esfuerzos y gestiones para favorecer lo que en su opinión era perdurable: la cultura.

\title{
3.2. ¿Qué hacer?
}

Durante sus funciones en la Secretaría de Educación, Chacón y Calvo manifestó una incesante preocupación por salvar la deuda con el pasado de la nación cubana desde el estudio y la divulgación de la obra de José María Heredia y Félix Varela. Insistió en hacer llegar de manera palpable clásicos de la literatura, el arte y la historia nacional a la población para evitar que su investigación estuviese exclusivamente destinada al reducido círculo de los expertos. En este sentido expresó que:

\begin{abstract}
"Todo ha de venir en esta concepción espiritualista y libre. Cuba es el centro de nuestras actividades. ¿Qué obligación de conciencia nos acucia el ánimo en primer término? Es un deber histórico: El Estado cubano en sus treinta años largos de vida independiente no ha sabido cumplir con sus grandes hombres con los maestros que a lo largo del siglo XIX formaron el pensamiento cubano de la patria, la conciencia de nuestra nacionalidad. No es suficiente que nuestros clásicos tengan una edición esmerada; es necesario que los hombres creadores de la cubanidad, los que formaron la conciencia de cubanidad dejen de ser personajes desvanecidos, esfumados para nuestro pueblo y los sintamos como figuras familiares con vigencia actual en lo más hondo de la conciencia colectiva" 57 .
\end{abstract}

Resulta evidente que los temas sobre Cuba siempre fueron motivo de preocupación para Chacón. Cuestionó el modo en que se gestionaban los recursos en las dependencias culturales de la Isla y la poca atención que recibían las necesidades educativas de la población, así como el detrimento que sufría la historia de la nación en los primeros años republicanos. Nos parece importante comentar que no existe relación entre su posición de neutralidad con la ausencia de crítica ante los problemas apremiantes de la nación.

Además, quiso dar continuidad a las Misiones Culturales con teatros- bibliotecas ambulantes, conciertos populares y con la distribución de los Cuadernos de Cultura. No obstante, no fructificaron del todo sus intentos porque no contó con los recursos económicos necesarios. Fundó la Revista Cubana desde donde pretendió recoger los valores genuinos de la nacionalidad indagando en el pasado y el presente. Por otro lado, organizó la Exposición Nacional de Pintura y Escultura en la que, cada año, se exhibirían las mejores obras del sector.

Sus inquietudes acerca de todas las dimensiones de la cultura, palpables ya en 1930 cuando acompañó a García Lorca en un viaje por el oriente cubano como parte de una visita organizada por la Hispano Cubana para el poeta español, se evidenciaron cinco años más tarde siendo ya oficialmente Director de Cultura. En 1935, organizó en La Habana el Tricentenario de la muerte de Lope de Vega convocando un concurso literario, recitales de poesías o la representación en la Plaza de la Catedral de Fuenteovejuna. Se debe tener en cuenta que en España se

57 Diario de la Marina, 11 de febrero de 1937. 
generó un movimiento de envergadura para conmemorar la fecha y que Menéndez Pidal estuvo al frente de la Junta del Tricentenario, por lo que no parece casual que fuera Chacón quien asumiera la organización de los festejos en Cuba ni el consiguiente brillo con que fueron celebrados. El periódico madrileño La Voz (1935, agosto) realizó una reseña extensa dando cuenta de todos los detallas de lo que aconteció en la Habana y resaltó la participación de Chacón lo que, además, demuestra el fluido intercambio de noticias existente entonces entre España y Cuba.

También fomentó programas radiales con fines educativos e instructivos donde el propio Juan Ramón Jiménez en 1936 leyó sus poemas inéditos. En 1937 trabajó arduamente para que se fundara el Instituto de Investigaciones que se inauguró con la conferencia de Claudio Sánchez Albornoz. También engrosarían el listado de los conferencistas figuras selectas como Menéndez Pidal, Pedro Salinas, con quien ya había coincidido en años anteriores en disímiles actividades en Madrid y Ots Capdequí, a quien conocía de su intercambio con el Instituto Hispano Cubano de Sevilla. Los nombres mencionados demuestran que los contactos que estableció en España contribuyeron al buen desenvolvimiento de sus tareas posteriores.

En su búsqueda incesante por el conocimiento, José maría Chacón y Calvo no distinguió entre la cultura de elite y la cultura popular. Sus ingentes esfuerzos por alcanzar lo genuino lo hicieron indagar en las raíces y las tradiciones. Gutiérrez Vega ha afirmado que se dedicó durante años a recoger cantares populares, adivinanzas, refranes y romances tradicionales ${ }^{58}$. En su deseo de rescatar una parte vital de la historia nacional llegó a realizar un viaje por todo el país en aras de recopilar la literatura popular. En febrero de 1923 fundó junto a Fernando Ortiz la Sociedad de Folklore Cubano. Años más tarde, cuando se encontraba en la Dirección de Cultura, trató de reactivar dicha Sociedad y ya en 1937 dejó establecido mediante decreto la Comisión de Folklore Cubano. En el propio año 1937 recorrió varias provincias de la Isla con Menéndez Pidal con el propósito de reorganizar los grupos folklóricos.

Teniendo en cuenta su decursar en la Secretaría de Educación cubana y la gestión que llevó a cabo en ella, resulta evidente que para Chacón la cultura era una necesidad esencial de la nación. Su interpretación sobre este ámbito fue amplia e incluyó, de forma unánime, tanto la creación intelectual como la difusión.

\subsection{Investigador histórico}

Para lograr una visión abarcadora sobre José María Chacón y Calvo es necesario conocer su labor como investigador. Por esa razón, su conferencia titulada El documento y la reconstrucción histórica, que impartió en el auditorio de la Institución Hispano Cubana de Cultura cuando transcurría el año 1929, recoge elementos que corroboran alguno de los señalamientos realizados hasta el momento.

Chacón ofreció significado especial al hecho de retornar al púlpito cubano después de once años de ausencia de su país, lo cual evidencia ese camino de doble sentido que fue natural y necesario para él a lo largo de su vida. Fue

\footnotetext{
58 GUTIERREZ VEGA, Zenaida. José María Chacón y Calvo. Op. cit., p. 66.
} 
precisamente la Institución Hispano Cubana el escenario escogido, lo cual simboliza una fase renovada en la relación cultural entre España y Cuba desde mediados de los años veinte. La edición impresa de esa conferencia está dedicada a su amigo Fernando Ortiz, a quien denomina "gran creador de cultura". Además declaró que hablaría de "aquello que ha sido el centro de mi vida en estos últimos años el documento y más específicamente, el documento histórico"59. A pesar de sus intensas experiencias en la Península como diplomático, una vez más, nos topamos con una frase que nos dibuja el peso decisivo que otorgó Chacón a su labor como investigador.

Considera el documento como una fuente tradicional y vital de la historia, opina que la interpretación que se hace del mismo reviste la misma importancia que el escrito en sí. Realizó un recordatorio de figuras del siglo XIX cubano como Domingo del Monte, Blas Oses o Tomás Agustín Cervantes, miembros de la Sección de Historia de la Sociedad Patriótica de Amigos del País. En el primer análisis comentó una carta del Rey Católico al Comendador fray Nicolás Ovando, gobernador de la Española, fechada en Valladolid el 14 de agosto de 1509. Lo significativo de la misiva para Chacón es que por primera vez apareció mencionada la figura de Sancho Camacho y un viaje secreto, a todas luces fuera de la ley, que realizó este hombre a Cuba. Al no existir constancia por historiador alguno del mencionado susodicho Chacón reclama que el nombre del desconocido se sume a los que precedieron a Velázquez en la colonización. Nos encontramos ante uno de los tantos ejemplos que le otorgaron la posibilidad de develar documentos históricos inéditos para la historia de Cuba.

En segundo lugar refiere, Los orígenes de la esclavitud africana en América y fray Bartolomé de las Casas, donde abordó los comienzos de la esclavitud al referir una recomendación explícita de sustituir a los indios por esclavos africanos según el legajo 139-1-4 del registro del Consejo de Indias en un documento de 1503 y el texto de la Provisión a los oficiales Reales de Sevilla. La intención de Chacón es corroborar y validar los criterios del historiador cubano José Antonio Saco en su Historia de la_esclavitud, además de respaldar la tesis que desmiente la relación directa del Padre Las Casas con la decisión de convertir en esclavos a los africanos.

En un tercer momento aborda, La servidumbre de los indios y los sermones de Montesinos, donde reflejó como a través de los relatos de Las Casas fue posible retratar los excesos de algunos frailes a los indios en La Española. Todo ello, explicó Chacón, generó un enfrentamiento de criterios entre el principio teológico defendido por los dominicos y el legalista esgrimidos por los conquistadores. Finalmente agrega, como es sabido, que los intentos de los dominicos por comunicar lo que sucedía no varió el statu quo.

Cuando alude al Archivo de Simancas se percibe su contrariedad por aquellos historiadores simplistas que solo se refugian en el Archivo de Indias lo cual conlleva a dejar inconclusa las obras e incompletos los análisis. Como ejemplo representativo de citado archivo menciona el gran caudal que se custodia sobre Francisco de

59 CHACÓN Y CALVO, José María. El documento y la reconstrucción histórica. La Habana: Editorial Hermes, 1929, p. 10. 
Miranda y específicamente la referencia que se localizó sobre Alejandro de O"Reilly, fundador del linaje cubano que llevó dicho apellido. Para Chacón fue oportuno conocer acerca la personalidad autoritaria del Conde y descifrar en las memorias del viajero y fundador de la estirpe de los O"Reilly su paso por Cuba en abril de 1764. Consideró que en esos escritos se pueden observar los gérmenes de las posteriores reformas hechas por el gobierno español en la Habana en el siglo XVIII.

Las conferencias de corte histórico impartidas por Chacón y Calvo permiten complementar la visión sobre su figura. Si en su etapa como Director de Cultura expresó su cercanía al acervo cultural español, cuando materializó su experiencia de investigación en la Península se vislumbró su permanente búsqueda por lo netamente cubano. Su faceta como investigador revela un historiador riguroso. Privilegió el período colonial en su acercamiento a la ciencia de Herodoto y dentro de dicha etapa otorgó al padre Las Casas un papel protagónico. En lo referente a su tierra natal, dedicó numerosos pasajes a recordar y homenajear a los para él imprescindibles intelectuales del siglo XIX cubano. No se detiene en la simple enumeración positivista, sino que persiste en análisis integradores. A través de un lenguaje ameno, Chacón se presentó como un viajero que anduvo por tierras españolas en busca de los detalles y acontecimientos que permitieron recomponer la historia de su propio país.

\section{Conclusiones}

José María Chacón y Calvo encaminó su quehacer de manera continua y fructífera hacia un hispanoamericanismo cultural que se retroalimentó de la experiencia en ambas orillas del Atlántico: España y Cuba. Su trabajo diplomático en tierras españolas fue el medio que le permitió desarrollar su pasión: la investigación exhaustiva y que le condujo a ampliar su visión histórica. Se puede constatar como Chacón se insertó de inmediato entre la élite cultural de la península con el respaldo de amigos y colegas proyectándose su labor a través de la prensa que, constantemente, reflejó obras de su autoría y los eventos en los que participó.

Desde su experiencia personal desdeñó la política como instrumento cultural, de ahí que abogara por la neutralidad de la cultura como método eficaz para transformar los valores educacionales y la conciencia cívica. En las redes establecidas por Chacón priman las relaciones establecidas entre colegas como demuestran los contactos que efectuó con investigadores e intelectuales. En segundo lugar potenció las redes de amistad devenidas en gran medida de las primeras. Consideremos que no fue la política lo que determinó su entorno porque es común encontrar entre sus allegados diferentes filiaciones. Las redes intelectuales creadas por Chacón y Calvo facilitaron la concreción de proyectos que retroalimentaron intercambios culturales de importancia entre la Mayor de las Antillas y España en la primera mitad del siglo XX.

\section{Fuentes Primarias}

Archivo de la Agencia Española de Cooperación Internacional para el Desarrollo. Biblioteca Hispánica. Colección José María Chacón y Calvo. 
Archivo Histórico Nacional, Sección del Ministerio de Relaciones Exteriores. Expediente Nacional de José María Chacón y Calvo.

Archivo de la Real Academia de la Historia. Depósito de Ramón Estalella.

Archivo digital de la Universidad de Yale. https://archives.yales.edu

\section{Fuentes Hemerográficas}

Ahora, 16 noviembre 1935.

Ahora, 14 de mayo 1936.

Cosmópolis, enero, 1922.

Diario de la Marina, 11 febrero 1937.

Diario de la Marina, 7 octubre 1958.

La Época, 11 de febrero 1922.

La Época, 3 de abril 1924.

La Época, 8 de marzo 1921.

La Época, 18 de abril 1928.

La Época, 27 de mayo 1922.

El Fígaro, 27 de enero de 1919, p. 14.

El Heraldo de Madrid, 1928.

El Liberal, 7 de marzo 1926

El Liberal, noviembre 1928.

La Nación, 22 de junio 1927.

La Nación, 23 de abril de 1934.

El Sol, 16 de noviembre de 1935.

La Voz, 9 de abril 1924.

La Voz, 19 de agosto 1935.

La Voz, 25 de septiembre de 1935. 


\section{Bibliografía}

AGUSTÍN SANCHÉZ, A. Entre la literatura y la diplomacia. La gestión de Vicente Riva Palacio en Madrid, 1886-1896. En: CAGIAO VILA, P. (comp.). Donde la política no alcanza. Madrid: Iberoamericana, 2018.

ALTAMIRA CREVEA, Rafael. Mi viaje a América. Oviedo: Universidad de Oviedo, 1910, (reedición 2007).

BALBOA PEREIRA P, Malena. Hacia una zona de convivencia de la cultura. José María Chacón y Calvo. Espacio Laical. 3/2011.

BALBOA PEREIRA, Malena. Contra la indiferencia oficial. José María Chacón Calvo, director de cultura (1934-1945). La Habana: Editorial letras cubanas, 2013.

BALBOA PEREIRA, Malena. José María Chacón y Calvo a la luz del pensamiento de Enrique José Varona. Cuadernos cubanos de Historia. Instituto de Historia de Cuba. 2015, vol. 22, n. 2.

BINNS, Nial; CANO REYES, Jesús y CASADO FERNÁNDEZ, Ana. Cuba y la guerra civil española. La voz de los intelectuales. Madrid: Calambur, 2015.

BUENO, Salvador. En Memoria de José María Chacón y Calvo. Revista de la Biblioteca Nacional José Martí [en línea]. Ene./abr. 1970, año 61, vol. XII, n. 1. Disponible en $<$ http://librinsula.bnjm.cu $>$.

BRUQUETAS DE CASTRO, Fernando. José María Chacón y Calvo o la cultura como diplomacia: Madrid, 1918-1936. En: CAGIAO VILA, P. y ELÍAS CARO, Jorge Enrique (comps.). España como escenario. Política y acción cultural de diplomáticos (1880-1936). Santa Marta: Unimagdalena, 2018.

CAGIAO, VILA. Pilar. En Prensa. Estudios Caldasianos: Ciencia y Nación. A 250 Años del Natalicio de Francisco José de Caldas. Cali, Colombia: Programa Editorial de la Universidad del Valle, 2018.

CHACÓN Y CALVO, José María. El documento y la reconstrucción histórica. La Habana: Editorial Hermes, 1929.

DíEZ HOLLO, María del Carmen. José María Chacón y Calvo en la Biblioteca Hispánica. Anuario Americanista Europeo. 2005, n. 3.

GREGORI TORADA, Nuria. José María Chacón y Calvo. Diario íntimo de la Revolución Española. La Habana: Instituto de Literatura y Lingüística, 2006.

GONZÁLEZ LÓPEZ, María Antonia. Índice de la Revista Raza Española. 2001, vol. 63, n. 126. 
GUILLAMA CAMBA, Ruxandra. Las Redes de la Cultura: El Instituto HispanoCubano de Sevilla (1928-1939). ¿Una apuesta por la transformación del americanismo? Sevilla: Instituto Hispano Cubano de Historia de América, 2018.

GUTIERREZ VEGA, Zenaida. José María Chacón y Calvo. Hispanista Cubano. Madrid: Ediciones de Cultura Hispánica, Madrid, 1969.

ORTIZ, Carmen. Zenaida Gutiérrez -Vega hispanista Cubana. Revista de Indias. 2009, vol. LXIX, n. 247.

JIMÉNEZ, José Olivio. Los cincuenta años de vida literaria de José María Chacón y Calvo. La Habana: Talleres del Archivo Nacional, 1964.

NARANJO OROVIO, Consuelo y SAMPER, Miguel A. Fernando Ortiz y las Relaciones Científicas Hispano-Cubanas, 1900-1940. Revista de Indias. 2000, vol. LX, n. 219.

ORTIZ, Fernando. La Reconquista de América. Reflexiones sobre el pan hispanismo. París: Sociedad de Ediciones Literarias, 1910.

SAINZ, Enrique. Breve recuento de la Revista Cubana. Revista Espacio Laical. 2018, año 14, n. 1.

VÉLEZ JIMENEZ, Palmira. Alfonso Reyes como "puente" de americanismo. En: CAGIAO VILA, P. y ELÍAS CARO, J.E. (comps.). España como Escenario. Política y acción cultural de diplomáticos latinoamericanos (1880-1936). Colombia: Unimagdalena, 2018, pp. 367-404.

VITIER, Cintio. José María Chacón y Calvo. Algunos recuerdos. Seis visiones y un recuerdo sobre José María Chacón. La Habana: Editorial Creat, 1995. 


\section{Anexos}

1. Designación de José María Chacón y Calvo en la Legación Cubana en Madrid durante el transcurso del año 1918. (Archivo Nacional de España)

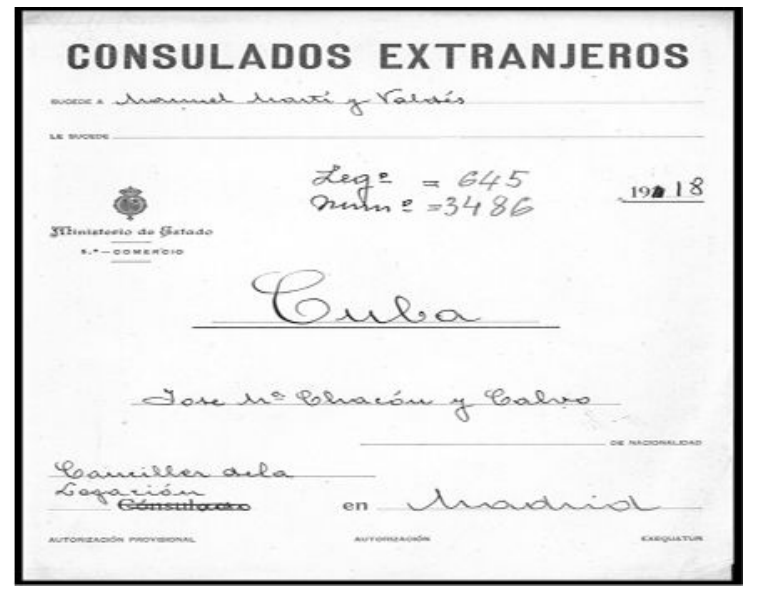

2. Nota verbal de la Legación Cubana en Madrid informando al Ministerio de Estado sobre la designación de José María Chacón y Calvo. (Archivo Nacional de España.

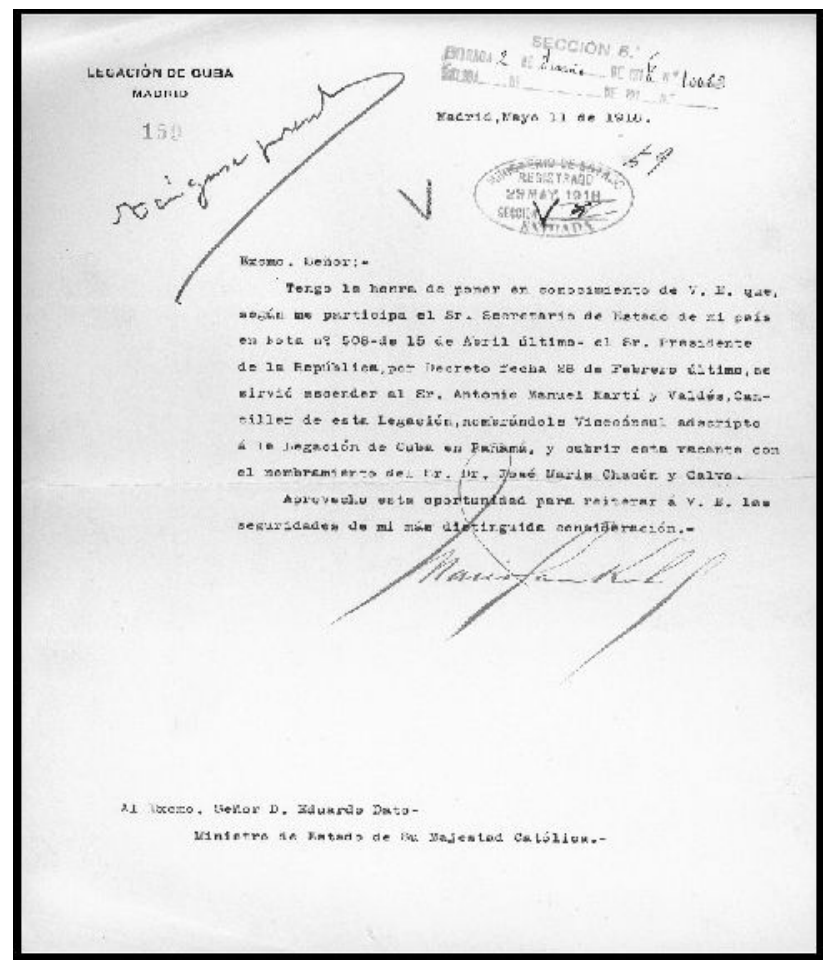

